\title{
Narrativa midiática e narrativa didática de história: caminhos entrecruzados na contemporaneidade
}

Media narrative and history didactic narrative: intersecting paths in contemporaneity

Sonia Maria de Almeida Ignatiuk Wanderley*

\section{Resumo}

$\mathrm{O}$ artigo apresenta algumas reflexões acerca da cultura histórica produzida/ permeada pela mídia e sua influência na produção do saber histórico escolar visando ao desenvolvimento de pesquisa aplicada em turmas de ensino fundamental. Considerando a crescente valorização da história e da memória nos espaços da comunicação midiática e a grande circulação dos significados produzidos por esses agentes na sociedade, torna-se fundamental o questionamento dos profissionais da história (professores/pesquisadores) acerca da influência das narrativas desenvolvidas por esses veículos no ensino da história escolar. Utilizo nessa reflexão autores e obras tanto do campo da Comunicação quanto da História, buscando bordar com eles uma teia de significados que permita construir metodologias para um mapeamento da relação que se estabelece entre a competência narrativa de uma escrita midiatizada da história e a escrita didática da história. Palavras-chave: cultura histórica; narrativa; saber histórico escolar.

\section{Abstract}

This article presents some of my reflections on the historical culture produced/ permeated by the media and its influence on the production of knowledge transcripts aiming at the development of applied research in elementary school classrooms. Given the growing appreciation of history and memory in spaces of mediated communication and wide circulation of meanings produced by these agents in society, it becomes fundamental the questioning of history professionals (teachers/ researchers) about the influence of the narratives developed by these vehicles on teaching school History. I use on this reflection authors and works from both the field of communication as well as History, trying to weave them in a web of meanings which allows building methodologies for mapping the relationship established between the narrative competence of a mediated writing of history and the didactic writing of history.

Keywords: historical culture; narrative; school historical knowledge.

\footnotetext{
* Departamento de Ciências Humanas e Filosofia (CAP) e Programa de Pós-Graduação em História Social, Universidade do Estado do Rio de Janeiro (Uerj). Rua Santa Alexandrina, 288, Rio Comprido. 20261-232 Rio de Janeiro - RJ - Brasil. soniamaiw@gmail.com
} 


\section{A CONSTITUIÇÃO DA CONSCIÊNCIA HISTÓRICA} NA CONTEMPORANEIDADE

A postura que adotamos com respeito ao passado, as relações que desenvolvemos entre passado, presente e futuro, não são apenas questões de interesse vital para todos: são indispensáveis. É inevitável que nos situemos no continuum de nossa própria existência, da família e do grupo a que pertencemos. É inevitável fazer comparações entre o passado e o presente: é essa a finalidade dos álbuns de fotos de família ou filmes domésticos. Não podemos deixar de aprender com isso, pois é o que a experiência significa. Podemos aprender coisas erradas - e, positivamente, é o que fazemos com frequência -, mas se não aprendemos, ou não temos nenhuma oportunidade de aprender, ou nos recusamos a aprender de algum passado algo que é relevante ao nosso propósito, somos, no limite, mentalmente

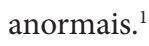

As palavras de Hobsbawm nos lembram de que o pensamento histórico é uma característica intrínseca à existência humana. A necessidade de conhecer o passado e relacioná-lo ao presente é algo imprescindível aos seres humanos por sua natureza. Essa epígrafe nos remete à ideia de que uma das funções da história é a de desnaturalizar o sentido que damos ao tempo e, com isso, desenvolvermos nossa consciência histórica.

O teórico da história alemão Jörn Rüsen ${ }^{2}$ considera que a consciência histórica é algo universalmente humano e articula, fundamentalmente, dois elementos: o passado como experiência e o presente e o futuro como campos de ação orientados por esse passado, tendo como função auxiliar a compreensão da realidade passada para entendimento da realidade presente. Dizer que a consciência histórica é algo inerente ao humano, portanto, não implica a negação de que ela seja mutável, melhor dizendo, a consciência histórica de cada indivíduo pode se tornar mais complexa por meio dos aprendizados que desenvolve em sua vida.

Rüsen é categórico quanto à importância da aprendizagem no desenvolvimento da consciência histórica e afirma a relação necessária entre aprendizado e experiência. Hobsbawm em seu texto situa muito bem a relação precípua entre o aprendizado e a experiência. Os dois autores nos indicam que a 
aprendizagem histórica pode ser explicada como um processo de mudança estrutural na consciência histórica.

O teórico alemão afirma, contudo, que o aprendizado que permite a apreensão da historicidade não se encontra vinculado unicamente a uma disciplina acadêmica ou escolar. Para esse autor, a aprendizagem escolar é apenas uma forma dentre outras de se desenvolver a consciência histórica. Todos os diálogos que os homens realizam com a natureza, com os demais homens e consigo mesmos acerca do que sejam eles próprios e seu mundo desenvolvem a consciência histórica. Daí a importância que ele dedica ao que considera a estratégia privilegiada desse desenvolvimento - a narrativa. ${ }^{3}$

Produzidas para dar significados às experiências dos homens no tempo, as narrativas são organizadas com base em competências diferenciadas. Rüsen compreende 'competência narrativa' como a habilidade para narrar uma história por meio da qual a vida prática recebe uma orientação no tempo.

Partindo desses pressupostos, devemos, pois, nos perguntar se estamos, enquanto profissionais da história - pesquisadores e professores -, sendo capazes de desenvolver e interpretar narrativas que, em sua constituição de sentido, se vinculem à experiência do tempo de maneira que o passado possa tornar-se presente no quadro cultural de orientação da vida prática contemporânea. Ou seja, se estamos nos preocupando com a resposta que nosso trabalho está oferecendo às demandas sociais por orientação em um mundo caracterizado por um processo frenético de mudanças.

Assumimos, aqui, um ponto de partida que caracterizará toda a reflexão que vamos desenvolver neste artigo - a discussão acerca das características de diferentes narrativas que se inter-relacionam durante o ensino de história no ambiente escolar e de que forma elas imprimem sua marca no desenvolvimento da consciência histórica dos alunos.

Esse objetivo nos obriga à reflexão acerca dos atuais problemas da escrita da história. Sem desconsiderar as especificidades do saber histórico escolar, ou a importância da narrativa midiatizada, carregada de memória, no atual contexto de nossas salas de aula, compreendemos que o elo entre o desenvolvimento da ciência histórica e o seu ensino escolar é o que permite ao professor a constituição de narrativas que possam desnudar as reificações perpetradas pelo senso comum que podem turvar o caráter social transformador da aprendizagem de história. 
Por isso mesmo devemos nos perguntar de que forma o desenvolvimento da ciência histórica em nosso país vem preocupando-se com a perspectiva apontada por Rüsen de que ensino e aprendizagem devam ser encarados como fenômeno e processo fundamental da cultura humana, não restritos simplesmente à escola. Considerando que o aprendizado histórico incorpora as experiências adquiridas na convivência com outras instâncias socializadoras nas quais estamos mergulhados cotidianamente e que dão forma ao que se convencionou chamar de 'cultura histórica', as reflexões em nossos espaços de trabalho, mormente aquele formador de professores para a escola básica, devem considerar obrigatoriamente essas outras narrativas constitutivas da 'cultura histórica'.

Estamos definindo 'cultura histórica' como uma forma específica de experimentar e interpretar o mundo, que descreve e analisa a orientação da vida prática, a autocompreensão e a subjetividade dos seres humanos. ${ }^{4}$ Pode-se, então, dizer que cultura histórica é o resultado de manifestações da consciência histórica articuladas em diferentes espaços socializadores nos quais se produzem interpretações diversas para a relação passado/presente/futuro por meio da construção de narrativas.

Sendo assim, em um mundo midiatizado como o atual será possível definir, de forma monopolista, a quem é dado o direito de produzir sentidos acerca do passado? Dar-lhe forma e expressividade, principalmente se levarmos em conta o presentismo reinante, aliado à 'sacralização' da memória e de seus lugares?

Não há dúvida de que pensar a história na contemporaneidade nos obriga a considerar a produção midiática, haja vista sua capacidade de produzir eventos e constituir sentidos. Assim, os campos da produção historiográfica - senhora, até há pouco tempo, da produção de sentido para o passado - e o da comunicação - no que tange à reflexão sobre sua capacidade na 'fabricação' de imagens simbólicas, conjunto de representações que forjam verdades/significados - se entrelaçam de tal forma no estabelecimento da cultura histórica que não podem, tanto historiadores, como jornalistas ou estudiosos da comunicação, deixar de refletir sobre a questão.

\section{NARRATIVA HISTÓRICA: ARTE E POLÍTICA}

Antes que os historiadores viessem a olhar para seu trabalho como uma simples questão de metodologia de pesquisa e antes que se considerassem 'cientistas', eles 
discutiram as regras e os princípios da composição da história como problemas de ensino e aprendizagem. Ensino e aprendizagem eram considerados no mais amplo sentido, como fenômeno e processo fundamental da cultura humana, não restrito simplesmente à escola. $\mathrm{O}$ conhecido ditado historia vitae magistra ... indica que a escrita da história era orientada pela moral e pelos problemas práticos da vida, e não pelos problemas teóricos ou empíricos da cognição metódica. (Rüsen, 2010, p.24)

Hoje, mais do que nunca, a história é uma disputa. Certamente, controlar o passado sempre ajudou a dominar o presente: em nossos dias, contudo, essa disputa assumiu uma considerável amplitude. De fato, a democratização do ensino e a difusão dos conhecimentos históricos por outros meios - cinema, televisão contribuem para esclarecer o cidadão, ao mesmo tempo sobre o funcionamento de sua própria cidade e sobre o uso e utilizações políticas da história ... Pois, na verdade, o Estado e o político não são os únicos a colocar a história sob vigilância. Também o faz a sociedade, que, por sua vez, censura e autocensura qualquer análise que possa revelar suas interdições, seus lapsos, que possa comprometer a imagem que uma sociedade pretende de si mesma. ${ }^{5}$

Nestes tempos ditos pós-modernos, a chancela de conhecimento científico que diferencia o saber produzido pela história e, para alguns, o seu ensino, necessariamente não os qualificaria a ter um reconhecimento social maior que o de outras formas de saberes, muitas das quais formatando o que é chamado de senso comum. Essa afirmativa vem caracterizando diversas reflexões acadêmicas nos dias de hoje.

Apesar de discordar dos fundamentos das críticas pós-modernas à ciência histórica, Rüsen acredita que tais questionamentos, longe de fortalecerem a perspectiva de que a história não detém mais lugar cativo enquanto explicação do passado, refundam conceitos definidores para a visão moderna de história, obrigando-nos, como profissionais, a considerá-los, com o rigor teórico e metodológico que caracteriza os estudos históricos, sem esquecer que a produção historiográfica não deve estar descolada dos problemas relacionados ao seu ensino e aprendizagem.

Aprendemos com os Annales que a história se faz com base no presente, sendo assim, uma das funções sociais da história (e aí incluímos o seu ensino) 
é produzir caminhos por meio dos quais a sociedade possa "atravessar o rio dos tempos", aprendendo a reconhecer-se nesses caminhos. Portanto, "uma das tarefas contemporâneas da história é ensinar e permitir a construção de maneiras de olhar o mundo, de perceber o social, de entender a temporalidade e a vida humana". ${ }^{6}$ Ou seja, cabe à história utilizar-se das ferramentas que possui e redescobrir-se em um momento de profundas mudanças e de novas demandas sociais, ainda turvas pela incerteza que caracteriza o nosso tempo.

Acontece que nos dias de hoje, e como nos lembra Rüsen, outros atores sociais assumem para si a tarefa de construir significados acerca do tempo e ensinar à sociedade de que formas o 'rio dos tempos' foi atravessado no passado ou poderá sê-lo, no futuro. Estabelece-se, então, uma disputa, mesmo que de forma velada ou inconsciente, entre a história, incluído o seu ensino, e esses outros atores, com destaque para os meios de comunicação de cultura de massa.

Uma das 'vantagens' que tais meios têm nessa disputa refere-se ao fato de que suas narrativas não se encontram determinadas por um saber metodizado científico. Embora também se estabeleçam com base em um conjunto de normas que procura garantir a sua inteligibilidade, as narrativas produzidas pelos meios de comunicação de cultura de massa funcionam dentro de um universo no qual dominam o lazer e o prazer dos sentidos, bem menos enfadonhos do que as regras científicas que cristalizaram a escrita da ciência histórica.

Se não devemos abrir mão do caráter científico de nossa disciplina - científico no sentido de ser um saber metodizado, que obedece a regras de produção coletiva e institucionalmente definidas, que implica o aprendizado do saber fazer -, isso não pode implicar o desconhecimento de que nosso ofício tem como resultado final a produção de uma narrativa. As tecnicalidades pedagógicas, por exemplo, não podem elidir o fato de que uma boa aula de história está assentada na capacidade do professor de urdir uma boa narrativa, em levar os alunos a construírem sentidos e significados para textos e relatos já tramados. (Rüsen, 2001, p.38)

Como esse aspecto está longe de se efetivar na narrativa histórica, seja na historiográfica ou mesmo na didática, a capacidade de produzir significados para a vida prática de indivíduos não iniciados é estonteantemente maior na narrativa da mídia. 
Mas, afinal, de onde vem essa quase certeza que se impõe - a de que a escrita profissional da história será sempre menos capaz de enlevar os espíritos, além do intelecto, e tornar mais agradável e fácil a construção de sentidos por parte de não iniciados no campo da história?

Certamente a resposta a essa indagação tem a ver com o fato de a história ciência ter recusado, a partir da segunda metade do século XIX, a 'história-narrativa' ou 'historicizante' que em momentos anteriores caracterizou a escrita da história. A narrativa era vista pelos historiadores científicos do século XIX como uma forma ingênua de escritura que não se adequava ao modelo das ciências naturais que se queria garantir à história. A narrativa didática da história seguia os mesmos rumos, presa que estava aos caminhos da ciência mãe que seguia "seu gosto sem consultar o do público".

Contudo, o que então se questionava na história-narrativa não era a forma pela qual o trabalho historiográfico se tornava concreto e sim o conteúdo desse trabalho: "o objeto primeiro do debate recaía no acontecimento e não na narrativa” (Hartog, 1998, p.200). Para Hartog, que se utiliza de Ricoeur em sua análise,

[O acontecimento] pertence a todos os níveis e pode ser mais precisamente definido como 'uma variante do enredo'. Tem-se aí uma nova confirmação de que rejeitar o acontecimento não significa fazer desaparecer a narrativa (nem o acontecimento), mas transformá-los ... Assim, a história não cessou de dizer os fatos e gestos dos homens, de contar, não a mesma narrativa, mas narrativas de formas diversas ... Também a história pode ser tratada como (e não reduzida a) um texto. (Ricoeur apud Hartog, 1998, p.201)

Ora, podemos questionar o porquê de essa narrativa ser tão árida aos não iniciados. Uma consideração importante nesse sentido foi apresentada por Guimarães em um texto no qual ele apresenta a história como Bildung. Tendo como base a formulação de Rüsen de uma didática da história, ${ }^{8}$ Guimarães agrega a preocupação relacionada ao seu ensino e busca na semântica do vocábulo alemão, que tem sua utilização primária no campo das artes, a ideia de que o papel da escrita da história é o de dar forma e expressividade. Diz ele:

A história formulada como Bildung contrapõe-se radicalmente a uma perspectiva de tecnicização do passado, reinscrevendo-a no campo artístico, em seu senti- 
do de criação, como forma de fazer frente a dois riscos importantes: o primeiro, a cientificização da história, entendida apenas por uma vertente metodológica ... segundo, a fuga do sujeito do campo de preocupações da reflexão histórica. Considerar a história nessa perspectiva significa não desvinculá-la dos processos didáticos voltados para a sua apresentação tendo em vista o público, necessariamente o ator central desse processo de conhecimento do passado, para quem essa tarefa de investigação deve ter algum sentido. (Guimarães, 2009, p.48-49)

\section{II}

Outro aspecto pertinente ao nosso questionamento inicial nos é dado por Ferro na epígrafe utilizada acima. Sua palavra nos lembra de que a vigilância à produção de significados sobre o passado não se faz apenas pelo Estado, com a história oficial. Diante da extensa produção sobre o modus vivendi contemporâneo, a necessidade de os ambientes produtores de conhecimento, em especial o escolar, refletirem as diferentes orientações de um mundo que reconhece (ou tolera) a diversidade de culturas que o compõe e o informacionalismo oriundo do desenvolvimento dos meios de comunicação de cultura de massa, a leitura clássica de Ferro nos faz pensar em como a preocupação didática com o 'politicamente correto' multicultural pode afastar as narrativas de caráter histórico produzidas nas escolas de um dos nossos objetivos mais primordiais - a formação da consciência histórica.

Até que ponto a confusão que se estabelece no senso comum, muitas vezes reificado pela mídia, entre o militante e o político tem afastado a prática docente de seu papel enquanto formadora de consciência história, como nos indica Rüsen? A busca do 'politicamente correto' midiatizado, afinal, está nos afastando da "tomada de posição política e da defesa de valores, mesmo quando não se está atento para esses aspectos" (Albuquerque, 2012, p.33).

Unindo a preocupação de Ferro à de Rüsen, entendemos que seja bastante profícuo ao pesquisador de história se debruçar sobre a diversidade de narrativas que compreendem a cultura histórica, mormente a midiática e a didática escolar, em busca do entendimento de como elas se entrelaçam no processo de ensino-aprendizagem de história. Como elas se aproximam ou se diferenciam do conhecimento histórico acadêmico. Essas pesquisas devem considerar 
a necessidade de compreender a diversidade da cultura histórica; porém, não podem descuidar do caráter político formador da educação histórica.

Como afirma Ferro, também a sociedade "censura e autocensura qualquer análise que possa revelar suas interdições, seus lapsos, que possa comprometer a imagem que ... pretende de si mesma”. O perigo de não se diferenciar/avaliar as formas com as quais a consciência histórica vem à tona, muitas delas simplificadoras ou reificadoras enquanto processo, é muitas vezes capaz de retirar do ensino de história seu caráter formador, em essência, político.

\section{CONSCIÊNCIA HISTÓRICA E CULTURA DA MEMÓRIA}

A reverberação do conceito de cultura histórica dentro e fora dos meios acadêmicos reflete o papel que a memória histórica vem adquirindo no espaço público. São exemplos desse processo o boom da patrimonialização nas sociedades contemporâneas e o sucesso popular das narrativas acerca do passado levadas a cabo pelos meios de comunicação de cultura de massa.

El concepto de cultura histórica aborda un fenómeno que caracteriza desde años el papel de la memoria histórica en el espacio público: me refiero al boom continuo de la historia, a la gran atención que han suscitado los debates académicos fuera del círculo de expertas y expertos, y a la sorprendente sensibilidad del público en el uso de argumentos históricos para fines políticos. ${ }^{9}$

Pierre Nora identifica como fator determinante no desejo de memória de nossa época a questão da mundialização, processo no qual os meios de comunicação de cultura de massa exercem papel primordial. Nora discorre acerca de um movimento de alteração do tempo, que passa a ser mais dinâmico. A duração do fato é a duração da notícia, o novo é quem comanda, propagando significado para a hegemonia do efêmero. Torna-se questão essencial, portanto, refletir acerca da importância adquirida pela memória na constituição de manifestações da consciência histórica que se apresentam no espaço da sala de aula e nas narrativas escolares produzidas no ensino de história.

Os historiadores franceses François Hartog e Jacques Revel demonstram muita inquietação com esse processo de valorização social da memória que, segundo eles, empurra o profissional da história para o espaço público, dá uma 
dimensão pública à ciência histórica, colocando o historiador diante da necessidade de discutir os usos viáveis do passado pelo presente, ou melhor, os "usos políticos do passado". ${ }^{10}$

Desde a década de 1980, Hartog vem escrevendo pequenos ensaios que anunciam sua tentativa de formular uma noção "que lhe permite conceituar a experiência de tempo" ${ }^{11}$ - o regime de historicidade. Ele nos explica:

Entendo essa noção como uma formulação erudita da experiência do tempo que, em troca, modela nossa forma de dizer e viver nosso próprio tempo. Um regime de historicidade abre e circunscreve um espaço de trabalho e de pensamento. Ele dá ritmo à escrita do tempo, representa uma 'ordem' à qual podemos aderir ou, ao contrário (e mais frequentemente), da qual podemos escapar, procurando elaborar outra. ${ }^{12}$

Partindo da noção de 'regime de historicidade', Hartog nos apresenta outra - o presentismo - que importa considerar em nosso objetivo de pensar o papel do ensino de história como promotor de consciência histórica em um mundo marcado pelo consumismo e pelo efêmero midiático. O autor assim caracteriza essa noção:

Nessa progressiva invasão do horizonte por um presente mais e mais ampliado, hipertrofiado, está claro que a força motriz foi o crescimento rápido e as exigências sempre maiores de uma sociedade de consumo, onde as descobertas científicas, as inovações técnicas e a busca de ganhos tornam as coisas e os homens cada vez mais obsoletos. A mídia, cujo extraordinário desenvolvimento acompanhou esse movimento que é sua razão de ser, deriva do mesmo: produzindo, consumindo e reciclando cada vez mais rapidamente mais palavras e imagens. (Hartog, 1996, p.135)

O foco de análise de Hartog está no que ele define como economia midiática do presente. Essa não cessaria de produzir e consumir o acontecimento, dando ao presente, afirma, no momento mesmo em que ocorre, a marca de já histórico.

Como vamos demonstrar mais adiante, acreditamos que a perspectiva da noção de presentismo apresentada por Hartog carrega um toque de nostalgia do que ele mesmo define como regime de historicidade moderno. Apesar 
disso, o conceito, sem pretender ser homogêneo e universal, como analisa Nicolazzi (2010, p.23), não deixa de ter utilidade:

Seu mérito e sua utilidade residem antes na sua capacidade em conceituar o tempo, torná-lo, de uma forma bastante particular, pensável e, sobretudo, representável ... As ideias de presentismo, com todas as suas fragilidades, são ainda uma formulação inquietante e que, por isso, aguçam a curiosidade.

\section{HistóRIA E MÍDIA}

Não há novidade alguma na apropriação do passado pelos meios de comunicação de cultura de massa. A começar, por exemplo, pela imprensa escrita, a utilização recorrente em diversos momentos de retrospectivas e edições comemorativas é prova da existência de uma dimensão histórica no jornalismo. Temos de lembrar que a formulação narrativa dos meios de comunicação tem uma dimensão temporal que se encontra necessariamente ligada ao regime de historicidade de sua época. ${ }^{13}$

Estudiosos da mídia, como o intelectual alemão Andreas Huyssen, demonstram preocupação com a forma como se concretiza essa apropriação nos dias de hoje. Segundo o autor, a ascensão de uma 'cultura da memória', para a qual o desenvolvimento da mídia tem papel significativo, tem a ver com a falência das utopias:

A reciclagem e exploração pela indústria cultural de tópicos relacionados à memória contribuem para a expansão de preocupações relativas à memória na esfera pública. Num sentido mais amplo, contudo, a maior parte da cultura contemporânea da memória, eu penso, resulta do naufrágio do imaginário de utopias futuras característico do século XX. ${ }^{14}$

Demonstrando paralelismo com o pensamento de Nora, Huyssen (2004, p.99) considera que nos dias de hoje tentamos combater o medo e o perigo do esquecimento com estratégias de sobrevivência de rememoração pública e privada: "O enfoque sobre a memória é energizado subliminarmente pelo desejo de nos ancorar em um mundo caracterizado por uma crescente instabilidade do tempo e pelo fraturamento do espaço vivido". 
Essa 'cultura da memória' seria, então, uma forma de compensar a perda de estabilidade do indivíduo no tempo presente, uma forma de combater a nossa profunda ansiedade com a velocidade da mudança e o contínuo encolhimento dos horizontes de tempo e de espaço.

Apesar da aproximação com a argumentação de Nora, o pensador alemão considera a solução teórica dos 'lugares de memória' de Nora conservadora, já que, partindo de um princípio binário de lugar versus meio, não consegue dar conta de um "deslocamento fundamental nas estruturas do sentimento, experiência e percepção" contemporâneas, funcionando sempre como um discurso nostálgico de perda. Para Huyssen (2004, p.101), esse deslocamento caracteriza o "nosso presente que se expande e contrai simultaneamente".

Apesar da ressalva, Huyssen (2004, p.101) considera que o discurso midiático tem participação ativa na constituição social dessa 'cultura da memória', mas, embora considere o jornalismo investigativo sério essencial para a construção pública de discursos de memória nacional, acredita que seu enquadramento temporal é necessariamente limitado ao presente e ao passado recente, por isso ele precisaria ser complementado pelo trabalho historiográfico.

Também no Brasil, recentes estudos na área da comunicação vêm reconhecendo uma série de impasses teóricos e problemas metodológicos quando o assunto é o estudo da interface entre a História e a Comunicação. A jornalista Ana Paula Goulart Ribeiro, em artigo que faz parte de uma obra coletiva que organizou em 2008, critica exatamente o predomínio, em grande parte dos trabalhos da área da comunicação, dessa perspectiva memorialista, constituindo "uma ideia de história orientada e baseada em grandes feitos, singularidades, particularidades dos grandes personagens" (Ribeiro; Herschmann, 2008, p.20). Embora reconheça a importância dos relatos memorialistas para a pesquisa na área da História da Comunicação, alerta para o perigo da 'cultura da memória', e, como Huyssen, aponta a necessidade de se problematizar essa supervalorização da subjetividade.

Em outro artigo, na mesma obra, a jornalista e professora Marialva Barbosa (2008) afirma que temos nos dia de hoje um alargamento do presente, possibilitando um distanciamento em relação ao passado que se materializa a partir de sua reconstituição como espaço mítico. Dessa maneira, os tempos idos instauram-se como 'universo de sonho', e sua relação com o presente, cada vez mais fluida, promove um desejo contínuo de revigoramento desses 
laços. Os meios de comunicação são pródigos na construção idealizada desses laços que caracterizam o atual regime de historicidade.

Recorrendo a François Dosse, Barbosa aponta o significado transitório que hoje se dá ao presente e a acentuação pitoresca de certo passado, visto como o verdadeiro, único:

O passado é apresentado como momento memorial que intensifica o presente, dilacerado por utopias, das quais a mais constante é a sua inclusão como nenhures, e no qual os recursos à tradição possuem apenas valor performativo. O passado convocado para o presente se distingue deste através de uma nostalgia a ser preservada em lugares e momentos próprios: lugares de museificação e momentos de celebração. (Barbosa, 2008, p.89)

Com base na conjunção de ideias que se estabelece nas leituras de historiadores contemporâneos e teóricos da comunicação, apresentamos uma questão que procura nos fazer retornar ao nosso objetivo inicial. Primeiramente, não se pode negar que a simplificação contemporânea da relação passado-presente-futuro é refletida na narrativa midiática, produzindo nos receptores uma leitura de senso comum do conhecimento histórico, já que a mídia o trata como doxa e não como episthéme, como informa Barbosa. Contudo, sem que se negue a necessidade de problematizar a cultura da memória vigente e o culto ao efêmero que caracteriza nossos dias, pode-se questionar até que ponto essas interpretações não seriam sintomas daquilo que elas mesmas se propõem analisar - o presentismo. E, se assim for, não estariam elas sendo construídas a partir de instrumentos de análise que não são capazes de dar conta desse novo tempo, momento que se caracterizaria, por exemplo, pela necessidade de repensarmos o que chamamos conhecimento?

\section{O SABER HISTÓRICO E OS DEMAIS SABERES}

Vamos utilizar as ideias de Barbero $^{15}$ na tentativa de desnaturalizar as dúvidas aqui enunciadas e refletir sobre elas. $\mathrm{O}$ que vemos em grande parte dos trabalhos que buscam caracterizar o saber escolar e sua relação com outros saberes, incluindo o conhecimento acadêmico, é, no mínimo, um silêncio quando se trata de discutir as transformações que a atual revolução tecnológica 
(comunicacional) está provocando nos modos de circulação do saber, e, no tocante aos saberes escolares, a defasagem destes em relação àquilo que Barbero denomina 'saberes-mosaicos'. ${ }^{16}$ Esses saberes se relacionariam aos saberes escolares, porém circulariam fora do ambiente educacional, sob a forma do que comumente denominamos informação, em contraponto ao conhecimento, que teria sua origem no ambiente escolar/acadêmico:

E frente a um alunado cujo meio ambiente comunicativo se 'impregna' cotidianamente desses saberes-mosaicos que, sob a forma de informação, circulam na sociedade, a escola, como instituição, tende, sobretudo, ao entrincheiramento no próprio discurso, uma vez que qualquer outro tipo de discurso é visto como um atentado a sua autoridade. (Barbero, 2008, p.237)

O que Barbero tenta demonstrar é que a atual revolução comunicacional provocou duas mudanças essenciais na forma como o conhecimento (que ele denomina saber) circula na sociedade. Em primeiro lugar, houve uma descentralização desse conhecimento. Ou seja, uma transcendência no tocante aos seus espaços tradicionalmente produtores/divulgadores:

O saber transcende os livros e a escola, entendendo por escola todo sistema educativo, desde o fundamental até a universidade. O saber transcende, sobretudo, aquele que sempre foi seu eixo durante os últimos cinco séculos: o livro ... Estamos diante de uma descentralização culturalmente desconcertante, cujo desconcerto é disfarçado por uma grande parte do mundo escolar de forma moralista ... Essa atitude não nos ajuda em nada a compreender a complexidade das mudanças que estão atravessando as linguagens, as escrituras e as narrativas. São essas mudanças que, na realidade, são as causas de o adolescente não ler, no sentido que os professores ainda entendem por ler, ou seja, somente livros. (Barbero, 2008, p.238)

A outra mudança, aponta Barbero, refere-se ao que ele denomina deslocalização e destemporalização dos saberes, de forma que estes deixam de ocupar apenas aqueles espaços antes legitimados socialmente para sua distribuição e aprendizado:

Não é que o lugar escolar vá desaparecer, mas as condições de existência desse lugar estão sendo transformadas radicalmente, não só porque agora tem que 
conviver com um monte de saberes-sem-lugar-próprio, mas porque o aprendizado se desligou da idade para se tornar contínuo, isto é, ao longo de toda a vida. (Barbero, 2008, p.237)

A consequência de todo esse processo seria a atenuação das fronteiras que separam o conhecimento do saber comum. Não apenas por meio da frenética divulgação científica produzida pela mídia, mas "pela crescente desvalorização da barreira que alçou o positivismo entre a ciência e a informação":

A disseminação designa o movimento de atenuação tanto das fronteiras entre as disciplinas do saber acadêmico, quanto entre esse saber e os outros ... A única saída encontra-se na articulação de conhecimentos especializados com aqueles outros que provêm da experiência social e das memórias coletivas. (Barbero, 2008, p.238-239)

Percebe-se que Barbero trabalha com um significado para conhecimento que engloba todo saber que é produzido em um lugar por ele denominado sistema educativo e que inclui a escola básica e a universidade. Sem dúvida alguma, já avançamos na reflexão acerca da especificidade dos saberes escolares e da relativa autonomia que estes desempenham em relação ao conhecimento acadêmico. Mas isso em nada modifica a importância da reflexão de Barbero. Ela nos obriga a incluir uma variável nova em nosso questionamento quando relativiza a diferença entre conhecimento e informação, tendo em vista o contexto caracterizado pela cultura da memória. Questiona as premissas que utilizamos na análise da influência das narrativas produzidas pela mídia e refletidas no ensino escolar de história.

Assim como a discussão que apontamos anteriormente em Rüsen, no tocante às críticas pós-modernas ao racionalismo que organiza a definição de conhecimento histórico, Barbero nos lembra de que nos dias de hoje não há como esperar que a realidade contemporânea, marcada pela desestabilização do sujeito cartesiano, seja constituída apenas pela capacidade de pensar e de raciocinar desse sujeito:

Hoje nos encontramos com um sujeito muito frágil, mais quebradiço, mas paradoxalmente muito mais obrigado a assumir-se, a ser responsável por ele mesmo em um mundo no qual as certezas no plano do saber, como no ético ou no político, são cada vez menores. (Barbero, 2008, p.240) 
Onde ficaria o saber histórico escolar em toda essa discussão? De que forma devemos compreendê-lo a fim de dar conta dessas novas exigências no tocante aos espaços/sujeitos produtores de saberes que interagem na tessitura da consciência histórica de docentes e alunos?

Acreditamos que o caminho é pensarmos o conhecimento não apenas na perspectiva de como ele é produzido, mas, ao mesmo tempo, como é comunicado, aí incluindo, ensinado. Essas duas facetas devem ser compreendidas como indissociáveis, um saber marcado pela transversalidade:

Esses saberes transversais criarão mal-estares profundos nas áreas especializadas de formação, pois entranham uma progressiva indefinição do que está amarrado e ordenado de maneira linear, transformando-o em um conjunto intertextual polissêmico e polifônico, já que transversais são os saberes que duram por todo o exercício da profissão e por toda uma vida. (Barbero, 2008, p.250)

A perspectiva de Barbero aproxima-o do que se convencionou denominar história pública, pensada como "a possibilidade da construção de um conhecimento pluridisciplinar atento aos processos sociais, às mudanças e tensões", tendo em vista a reflexão "sobre a atuação do profissional capaz de estimular a consciência histórica para um público amplo, não acadêmico". ${ }^{17}$

A partir daí, nosso olhar sobre a repercussão da narrativa midiática na produção do saber histórico escolar ganha novos contornos, pois tentamos decifrar o hibridismo desse saber considerando sua produção e sua divulgação/ ensino como metades de um todo, ao mesmo tempo sujeito e projeção de uma nova temporalidade.

Temporalidade que não nos permite ignorar o atual esfacelamento de memórias e identidades estáveis, sejam elas individuais ou de grupos sociais. As velhas abordagens de cunho sociológico, diz Huyssen, não dão conta dessa dinâmica tão bem aparelhada pelas novas tecnologias da mídia, que, embora também reflexo desse contexto, cada vez mais amplia a sua capacidade de forjar a percepção social e política do mundo:

As contrastantes e cada vez mais fragmentadas memórias políticas de grupos sociais e étnicos específicos permitem perguntar se ainda é possível, nos dias de hoje, a existência de formas de memória consensual coletiva e, em caso negativo, 
se e de que forma a coesão social e cultural pode ser garantida sem ela. (Huyssen, 2004, p.19)

Portanto, o fazer do professor e pesquisador do ensino de história deve, entre outras ações, levar em consideração a relação que se estabelece entre memória e história nas narrativas midiatizadas da história, entendendo que, apesar de nossas memórias cada vez mais estarem sendo modeladas pelas tecnologias midiáticas, nunca serão redutíveis a estas. Dessa forma, devemos pensar como pode ser a nossa práxis visando à conformação da consciência histórica:

Se nós estamos, de fato, sofrendo de um excesso de memória, devemos fazer um esforço para distinguir os passados usáveis dos passados dispensáveis. Precisamos de discriminação e rememoração produtiva e, ademais, a cultura de massa e a mídia virtual não são necessariamente incompatíveis com este objetivo. (Huyssen, 2004, p.37)

\section{NOTAS}

${ }^{1}$ HOBSBAWM, Eric. Sobre a História: ensaios. São Paulo: Companhia das Letras, 1998. p.36.

${ }^{2}$ RÜSEN, Jörn. Razão histórica: teoria da história - fundamentos da ciência histórica. Brasília: Ed. UnB, 2001.

${ }^{3}$ Entenda-se narrativa como um processo de fazer ou produzir uma trama da experiência temporal tecida de acordo com a necessidade da orientação de si no curso do tempo. O produto desse processo narrativo, a trama capaz de tal orientação, é 'uma história' (RÜSEN, 2001).

${ }^{4}$ CARDOSO, Oldimar. Por uma definição de didática da história. Revista Brasileira de História [eletrônica], São Paulo, v.28, n.55, p.153-170, 2008.

${ }^{5}$ FERRO, Marc. A história vigiada. São Paulo: Martins Fontes, 1989. p.1-2.

${ }^{6}$ ALBUQUERQUE JUNIOR, Durval Muniz de. Fazer defeitos nas memórias: para que servem o ensino e a escrita da história? In: GONÇALVES, Márcia de A. et al. (Org.). Qual o valor da história hoje? Rio de Janeiro: Ed. FGV, 2012. p.31.

${ }^{7} \mathrm{O}$ interessante é perceber que é exatamente nesse momento que a história é pensada como disciplina ensinável - "uma matéria efetivamente organizada sob um sistema que prevê seu ensinamento, sua transmissão". GUIMARÃES, Manoel Luiz Salgado. Escrita de história e ensino de história: tensões e paradoxos. In: ROCHA, Helenice; SOUZA, Marcelo 
de; GONTIJO, Rebeca (Org.). A escrita da história escolar: memória e historiografia. Rio de Janeiro: Ed. FGV, 2009. p.35-50. p.36; HARTOG, François. A arte da narrativa histórica. In: BOUTIER, Jean; JULIA, Dominique. Passados recompostos: campos e canteiros da História. Rio de Janeiro: Ed. UFRJ; Ed. FGV, 1998. p.193-202. p.199.

${ }^{8}$ Rüsen considera a didática da história uma disciplina do campo historiográfico que analisa os fundamentos da educação histórica. Expandindo seus objetos de estudo para além do ensino e aprendizagem na escola, considera como problemáticas dessa disciplina "todas as formas e funções do raciocínio e conhecimento histórico na vida cotidiana, prática”. RÜSEN, Jörn. Didática da história: passado, presente e perspectivas a partir do caso alemão. In: SCHMIDT, Maria Auxiliadora; BARCA, Isabel; MARTINS, Estevão de Resende (Org.). Jörn Rüsen e o ensino de história. Curitiba: Ed. UFPR, 2010. p.23-40.

${ }^{9} \mathrm{O}$ texto está disponível em: www.culturahistorica.es/ruesen/cultura_historica.pdf.

${ }^{10}$ HARTOG, François; REVEL, Jacques (Ed.). Les usages politiques du passé. Paris: Éd. de l'ÉHESS, 2001. p.20.

${ }^{11}$ NICOLAZZI, Fernando. O tempo do sertão, o sertão no tempo: antigos, modernos, selvagens. Leitura de Os Sertões. Anos 90, Porto Alegre, v.17, n.31, p.261-285, jul. 2010.

${ }^{12}$ HARTOG, François. Tempo e história: como escrever a história da França hoje? Trad. Ana Cláudia Fonseca Brefe. História Social, Campinas (SP), n.3, p.127-154, 1996. p.129.

${ }^{13}$ BARBOSA, Marialva. Meios de comunicação e usos do passado: temporalidade, rastros e vestígios e interfaces entre Comunicação e História. In: RIBEIRO, Ana Paula Goulart; HERSCHMANN, Micael. Comunicação e História: interfaces e novas abordagens. Rio de Janeiro: Ed. Mauad X; Globo Universidade, 2008. p.83-96.

${ }^{14}$ HUYSSEN, Andreas. Mídia e discursos da memória. Revista Brasileira de Ciências da Comunicação, v.27, n.1, p.97-104, 2004. p.98.

${ }^{15}$ MARTÍN-BARBERO, Jesus. Saberes hoje: disseminações, competências e transversalidades. In: GOULART; HERSCHMANN, 2008, p.237-252.

${ }^{16}$ Essa discussão é desenvolvida por Barbero em artigo inicialmente publicado na Revista Ibero-americana de Educação [eletrônica], Madrid: OEI, n.32, 2005. Disponível em: www. rieoei.org/rie32a01.htm; Acesso em: 10 fev. 2011. Sua tradução para o português encontra-se em RIBEIRO; HERSCHMANN, 2008.

${ }_{17}$ ALMEIDA, Juniele Rabelo; ROVAI, Marta Gouveia de Oliveira (Org.). Introdução à história pública. São Paulo: Letra e Voz, 2011. p.7.

Artigo recebido em 20 de dezembro de 2012. Aprovado em 14 de abril de 2013. 